\title{
Pilot project purgatory? Assessing automated vehicle pilot projects in U.S. cities
}

\author{
Devon McAslan (10 ${ }^{1 凶}$, Farah Najar Arevalo (D) ${ }^{2}$, David A. King (iD ${ }^{2} \&$ Thaddeus R. Miller $^{3}$
}

Pilot projects have emerged in cities globally as a way to experiment with the utilization of a suite of smart mobility and emerging transportation technologies. Automated vehicles (AVs) have become central tools for such projects as city governments and industry explore the use and impact of this emerging technology. This paper presents a large-scale assessment of AV pilot projects in U.S. cities to understand how pilot projects are being used to examine the risks and benefits of $A V s$, how cities integrate these potentially transformative technologies into conventional policy and planning, and how and what they are learning about this technology and its future opportunities and risks. Through interviews with planning practitioners and document analysis, we demonstrate that the approaches cities take for AVs differ significantly, and often lack coherent policy goals. Key findings from this research include: (1) a disconnect between the goals of the pilot projects and a city's transportation goals; (2) cities generally lack a long-term vision for how AVs fit into future mobility systems and how they might help address transportation goals; (3) an overemphasis of non-transportation benefits of $\mathrm{AV}$ pilots projects; (4) AV pilot projects exhibit a lack of policy learning and iteration; and (5) cities are not leveraging pilot projects for public benefits. Overall, urban and transportation planners and decision makers show a clear interest to discover how AVs can be used to address transportation challenges in their communities, but our research shows that while AV pilot projects purport to do this, while having numerous outcomes, they have limited value for informing transportation policy and planning questions around $A V s$. We also find that AV pilot projects, as presently structured, may constrain planners' ability to re-think transportation systems within the context of rapid technological change.

\footnotetext{
${ }^{1}$ Chalmers University of Technology, Gothenburg, Sweden. ${ }^{2}$ Arizona State University, Tempe, AZ, USA. ${ }^{3}$ University of Massachusetts Amherst, Amherst, MA, USA. 凶email: devon.mcaslan@chalmers.se
} 


\section{Introduction}

utomated vehicles (AVs) have developed from an idea to reality over the last decade, which has led to substantial scholarly and policy interest about how cities should incorporate them in planning activities (e.g., Duarte and Ratti, 2018). AVs are being tested in dozens of cities in the U.S. and worldwide (Bloomberg Philanthropies, 2019; Haque and Brakewood, 2020), and even providing commercial services, such as Waymo One in the Phoenix metropolitan area (Khoury, 2018). Many cities are experimenting with these technologies in pilot projects to assess how AVs may help them achieve transport goals, gauge public interest in AVs, and evaluate potential use cases. The AV industry promotes the technology as a transformational technology that will make our roads safer, less congested, and change the way we travel in cities and society as a whole (Chase, 2014; Pankratz et al., 2018; Grush and Niles, 2019). Transportation policy and planning literature generally support this perspective (e.g., Tettamanti et al., 2016; Duarte and Ratti, 2018; Nikitas et al., 2021), with the caveat that urban and regional planning organizations need to be engaged with the AV industry to effectively plan for and manage this emerging technology (Creger et al., 2019; Legacy et al., 2019; Steckler et al., 2021). Others, including science and technology studies scholars, are more skeptical, interrogating assumptions about human behavior, politics, and the surrounding environment that get built into the algorithmic and technological components of AVs (Stilgoe, 2018a, 2018b; Stilgoe and Cohen, 2021) and challenging the purported benefits of a technological fix to complex urban problems (Bailey and Erickson, 2019).

Despite support for including AVs in planning efforts, to date only a few cities in the U.S. have incorporated AVs into their long-range planning efforts (Freemark et al., 2019). In the face of uncertainty about the impacts and growing skepticism about deployment timelines, many cities find it easier to not plan at this early stage. Others have recognized the need to plan and have begun to develop policies to help prepare for AVs, particularly regional planning agencies (McAslan et al., 2021). Some cities have created their own regulation and rules for testing, while others have adopted broader policy initiatives for emerging technologies (e.g., SDOT, 2017; City of Portland, 2018; City of Pittsburgh, 2019). Most common, however, is the use of AV pilot projects.

Pilot projects offer the opportunity for AV companies to test and develop the technology in a real-world setting. Pilot projects have the potential to offer cities an opportunity to capitalize on this real-world testing, to benefit from the operation of AVs now, begin to understand how AVs could transform their transportation systems, and to learn what types of policies they must adopt to maximize the benefits of AV technology and minimize the negative impacts. However, this approach of using AV pilot projects as a form of urban experimentation (Savini and Bertolini, 2019) threaten to limit public discussions about an automated mobility future. The extent to which pilot projects are being deployed in a way that can help cities understand how AVs can help them meet their transportation goals and to develop the policies necessary to achieve this is unclear.

This paper investigates how cities are using pilot projects as an urban planning and policy tool to learn about how AVs can help them meet their transportation goals (e.g., around safety, congestion, equity, sustainability, etc.), how AVs fit into their transportation futures, and to develop policy to guide the development and deployment of AVs. Specifically, we ask what are the major trends among cities using pilot projects as a planning tool and are these emerging approaches likely to have a positive impact on planning efforts? The focus on pilot projects stems from recognition that nearly 50 percent of cities planning for AVs are using (or have used) pilot projects -27 of 58 cities sampled use pilot projects. This paper draws on interviews and document analysis from 20 of these 58 cities. In this paper, we examine the decision-making processes behind why cities develop AV pilot projects, what their motivations are for developing pilot projects, and how their pilots are anticipated to inform future planning actions.

\section{Planning for autonomous vehicles within the smart city}

Autonomous vehicles, an emerging type of smart mobility, serve as a lens for deepening our understanding of the smart city, which in the last decade has become a dominant urban imaginary (Cugurullo, 2018). In the smart city, technological progress is linked to progress on environmental and social sustainability (Miller, 2020) and is acted upon by both a technology push, whereby technology companies market smart solutions to cities and a demand pull, where cities are seeking ways to become more efficient, inclusive, and sustainable (Angelidou, 2015). The current state of AVs exhibit both types of push and pull forces. Through the application of technology, governing the smart city becomes a technocratic way of governing (Kitchin, 2014; Bina et al., 2020). Verrest and Pfeffer (2019) critique the emergent academic field of smart urbanism for similarly considering the smart city as a "set of technocratic solutions to urban problems and not as a political response to political conflicts (p. 1329)." Other critiques emphasize how a technological and hyperrationalized approach to urban problems reproduces existing inequities in society (Krivý, 2018; Clark, 2020) and that by doing so, produces new visions of what a good city is and the role of citizens within that system (Vanolo, 2014).

Within smart cities, urban experimentation and pilot projects become important technical tools. Savini and Bertolini (2019) argue that political biases and normative assumptions are inherent in these urban experiments but that they are often overlooked. Smart mobility (Docherty et al., 2018), as a specific sector within the smart city, has been particularly prone to urban experimentation and has seen a proliferation of small- and largescale pilot projects to address urban transportation challenges. Even without the influence of smart city logics, transportation challenges are often framed as technical problems and less likely as social or political ones, and the smart city has further entrenched this thinking within the transport sector. Docherty et al. (2018) argue that the transition to smarter mobility futures is well underway, and that the current debate should not be about "state versus non-state actors but instead about the role the state takes within these new networks to steer, facilitate and also reject different elements of the mobility system (p. 123)." Recent innovations in AV technology emphasize this point. Cugurullo et al. (2021) demonstrate that the diffusion of AVs results from the interconnections between social attitudes, technological innovation, and urban politics.

Despite increasing recognition that the development of AVs exists within complex urban systems and should be subjected to rigorous public discourse (Stilgoe, 2018b), a majority of academic research does not address these issues. In fact, much of the research on AVs has focused on implications of the technology in order to reduce uncertainties and plan mobility systems and infrastructure investments, perpetuating the perspective that AVs are a technological fix to complex urban transportation problems. These studies may focus on shifts in travel behavior, including how people will travel (Harper et al., 2016; Harb et al., 2018; Soteropoulos et al., 2019), where they might live (Gavanas, 2019; Zhang and Guhathakurta, 2021), and changes in ownership (e.g., owning versus sharing) (Gruel and 
Stanford, 2016; Daziano et al., 2017; Zhang et al., 2018; Gao et al., 2019). Other research examines attitudes towards AV adoption (Haboucha et al., 2017; Hulse et al., 2018; Jin et al., 2020; Acheampong et al., 2021), which inform travel behavior models used to direct investment decisions. Research has also examined potential land use impacts (Fagnant and Kockelman, 2015; Hawkins and Nurul Habib, 2019; Soteropoulos et al., 2019) and shifts in parking requirements (Duarte and Ratti, 2018; Millard-Ball, 2019) as a result of travel behavior changes and considered how the built environment might be changed due to AVs (Cugurullo et al., 2021). Much of this research tends to consider AVs within the framework of existing transportation systems and assumes their eventual adoption as predetermined and overlooks the fact that the development of AVs is not simply a technological matter (Bissell, 2018).

The AV industry promotes AVs as potentially transformative for urban transport (Chase, 2014; Cugurullo et al., 2021). Boosters state that the parallel innovations of autonomy, connected, electric, and shared (ACES) will create a sustainable mobility future with less congestion, more safety, more accessibility, lower costs, and other benefits (Chase, 2014; City of Portland, 2018; Adler et al., 2019). Changes in ownership will reduce the number of vehicles in cities (Zhang et al., 2018), which may mean less need for parking (Crute et al., 2018). Streets can also be made more efficient, providing more space for other users, particularly pedestrians and cyclists (Crute et al., 2018; Kisner et al., 2019). These possible changes have driven visions of the future livable city (Knorr, 2018) and possible ways to redesign streets and public space (Kisner et al., 2019). Johnson and Riggs (2019) offer three principles to enable these transformations: adapt spaces for people, create sustainable and resilient places, and be actionoriented. These approaches aim to think about AVs as a new type of mobility, but they remain speculative about how these transformations in mobility systems may come about.

AV policy and regulation. Understanding the range of policy implications of AVs on transportation and cities has been a focus of research efforts (Lari et al., 2015; Fraedrich et al., 2019; Litman, 2020). Gruel and Stanford (2016) consider benefits and risks of $\mathrm{AVs}$ as well as speculative scenarios and possible policy interventions. Yigitcanlar et al. (2019) provide a snapshot of vehicle automation and its potential, however they affirm city planners are unprepared and without relevant research and suggest ways to mitigate risks and other social considerations. They call for planners to mitigate built environment and land use disruption by creating principles and funding studies, mitigation strategies, and context-based research.

Presently, policy and regulation regarding AVs in the U.S. is a combination of local, state and federal, with many cities taking a more active role since many states and the federal government have been slow to enact any sort of regulation or policy for AVs, even around basic safety of the vehicles (Brown et al., 2018). In this vacuum, numerous organizations have developed policy guidance for cities, such as the American Planning Association (APA) (Crute et al., 2018), National League of Cities (National League of Cities, 2017), Deloitte (Pankratz et al., 2018), TRB (Zmud et al., 2017), and others. Much of this policy guidance builds on the possible negative impacts of AVs and how existing policies may contribute to this. An APA report (Crute et al., 2018), for example, suggests that cities use policy as a necessary way to address the possible negative impacts of AVs. The report suggests that to combat sprawl, cities should discourage autooriented sprawl and rethink parking; or, to address possible increases in VMT or vehicle emissions, cities can promote shared AVs and develop policies for providing pick-up and drop-off zones and building these into new zoning codes (Crute et al., 2018). Chatman and Moran (2019) examined ten cities and regions known to have significant $\mathrm{AV}$ testing and piloting. Through examination of planning documents and interviews, they identified several key policy areas these cities are thinking about, including curb management, smart streets, integration with public transit, zoning codes and parking, and roadway charges.

Analyzing regional policy and planning approaches, McAslan et al. (2021) find that MPOs have begun to develop policies within their regional transportation plans for AVs. These include policies for infrastructure investment and maintenance, ensuring roadway safety for all users, data-sharing, encouraging multimodal transportation and public transit use, land use and parking, equity, and developing partnerships and collaborations as a key planning approach.

Freemark et al. (2019) found that few local governments have begun planning for AVs, that cities with larger populations and higher population growth are more likely to be prepared, and that although local officials are optimistic about the technology and its potential to increase safety while reducing congestion, costs, and pollution, more than a third of respondents worried about AVs increasing vehicle miles traveled and sprawl while reducing transit ridership and local revenues. Freemark et al. (2020) surveyed urban planners about support for various policies, identified in the literature, finding strong personal support among survey respondents for 10 of the 12 policies, but respondents indicated that there was often a lack of capacity and resources to develop these policies.

Karlin-Resnick et al. (2019) examine the early actions taken by cities on new mobility (AVs, ride-hailing, and others), looking at early policy moves, pilot projects, and autonomous transit, and identify main ways cities are thinking about policy. These include clarifying values, increasing investment in bike, pedestrian and transit planning, curb management, modernizing parking regulations, establishing data protocols, putting an emphasis on equity, reorganizing government around mobility, and proactively preparing for the future of work.

These efforts demonstrate many concerns that cities have as they attempt to mitigate the possible negative impacts of AVs. This work also highlights that in addition to numerous policy issues being particularly relevant to cities, there are numerous approaches to developing policy. These different approaches have included developing regulatory frameworks (or being required to adhere to state regulation), new ordinances (typically around zoning codes), developing mobility playbooks that develop goals and principles for AVs and other new technologies, and conducting new mobility pilot projects.

AV planning and pilot projects. The use of pilot projects is a common way for cities to test new transportation infrastructure, particularly with the advent of practices like tactical urbanism, which promotes low cost and flexible solutions (Talen, 2015; Webb, 2018). Pilot projects aim to test or develop new solutions to address urban sustainability issues, improve the effectiveness of urban services, and enhance quality of life. Pilot projects have become even more pronounced, particularly within the framework of urban living labs (Bulkeley et al., 2016, 2019) and smart cities (Angelidou, 2015; Verrest and Pfeffer, 2019) and are seen as a key way to achieve sustainability transitions (Huguenin and Jeannerat, 2017; von Wirth et al., 2019). The goal of pilot projects is to test technologies, their applications, infrastructures, and even policies on a small scale with the intention of scaling up those that are deemed successful. However, many of these smart city pilot projects fail to produce scalable solutions and this is widely seen 
as problematic (van Winden and van den Buuse, 2017; van den Buuse et al., 2021).

Bloomberg Philanthropies has monitored what cities are doing worldwide, distinguishing between those that are "piloting" technology and "preparing". In 2019, they had identified 30 out of 51 U.S. cities that were piloting AVs (Bloomberg Philanthropies, 2019). In a comprehensive review of new mobility pilots, which included micro-mobility, TNC partnerships, microtransit, passenger AVs and AV delivery, Steckler et al. (2020) identify key goal areas for these pilots. They find that micromobility, TNC partnerships and micro-transit tend to emphasize transportation goals, while AV pilot project goals tend to focus on assessing viability of the technology, gauging public interest, identify possible use cases, testing the technology, or simply to be innovative (Steckler et al., 2020). While their overall analysis is based on multiple AV pilots, they only provide two cases studies of these types of pilot projects.

Haque and Brakewood (2020) provide a comprehensive overview of AV shuttle pilot projects in the U.S., examining a total of 19. They find significant variation in the locations of pilot projects, service characteristics, and stakeholders involved. This echoes the findings of Dowling and McGuirk (2020) who differentiate between four types of AV experimentation approaches: on-road, test beds, precincts, and living labs. They find that each of these different approaches engages different combination of actors and different testing focuses (e.g., vehicle communication versus firstlast mile transport), which has implications for the outcomes of each pilot project.

Similarly, Mahmoodi Nesheli et al. (2021) review 33 AV shuttle pilot projects from around the world (8 from the U.S.) and find that a small number of pilots operate outside of highly controlled environments and that most are not yet integrated with existing public transit systems, although several plan to do this in the future. They find that while AV pilots have generally received positive feedback, those who have ridden AV shuttle pilots are not likely representative of the broader public, particularly the public that relies on public transit. They therefore recommend that future AV pilot projects move towards operating in more dynamic urban environments, exploring better integration and coordination with existing public transit, and increase accessibility of the pilots to a broader public (Mahmoodi Nesheli et al., 2021).

A critical perspective on pilots. Thus far, our review of AV pilots, policy, and planning efforts has focused on research that has tended to be more empirical and descriptive-reporting on policy developments, cases, and typologies. This work provides a thorough accounting of how AVs are being approached by policy and planning organizations across scales in the U.S. and beyond. These studies and many of the planning approaches they examine, rarely question the social and political assumptions embedded into AV projects. For example, how will AVs impact a municipality's carbon goals? Will AVs further entrench transportation inequalities? Specifically, much of this work and many pilot projects are often framed as purely technical endeavors-focusing on technological feasibility, operations, and interoperability. Such narrow framing closes out questions about social values and alternative goals and priorities that may shape how AVs are used in different ways. There is a large and rapidly growing literature that brings these and other such critical questions to the fore that has increasingly focused on how emerging and smart technologies and urban experimentation embed certain sets of politics at the expense of a broader set of political values (Sadowski and Pasquale, 2015; Miller, 2020; Sadowski, 2020).
Urban experimentation has become a common tool for city governments to use to address social and environmental problems (Bulkeley and Castán Broto, 2013). Scholars from critical geography, science and technology studies, and sustainability transitions have explored how urban experiments can be a space to test, learn and, potentially, scale up projects, policies and practices that may be able to address a wide range of urban challenges (Shove and Walker, 2007; Karvonen et al., 2014; Bulkeley et al., 2016).

Despite the potential benefits of urban experiments, Torrens and von Wirth (2021) show how such experiments are often insufficiently linked to policy learning, lack long-term funding, or are unable to scale. This leads to what they call a "projectification" of urban experiments, limiting the ability of such projects or pilots to create the long-term changes needed for addressing urban challenges (Hodgson et al., 2019; Torrens and von Wirth, 2021). This "projectification," particularly with regards to smart city technologies, are often framed as focused narrowly on technical feasibility while also carrying embedded assumptions about the proper uses of these technologies (Kitchin, 2021). These embedded assumptions and politics, or what Hecht (2001) calls techno-politics, also close-down alternative pathways for experimentation.

Torrens and von Wirth (2021) develop a schematic framework for distinguishing between projectifiction that can reinforce existing structures with a short-term focus on technical dimensions and limiting the ability to learn from experiments versus a more generative projectification that links continuous forms of experimentation and looks beyond project-based work toward longer-term transformative change. The literature on urban experimentation and projectication would have researchers, planners and policy-makers examine this more closely and ask how AV pilots are linked to policy learning and broader sets of goals related to transportation planning and urban development.

Overall, efforts around planning for AVs have predominantly attempted to understand the potential impacts of this technology on cities in an effort to reduce uncertainty. Numerous reports and academic studies have begun to document these pilot projects and to synthesize lessons learned. Many of these have focused on developing typologies of projects rather than on the processes and decision-making from the city perspective. However, critiques of smart cities and the increasing 'projectification' of urban mobility, raise the question of whether these types of projects are effective tools for planning. This paper is an attempt to advance the literature on new mobility pilot projects to understand how local governments are utilizing pilot projects and examine the extent to which they are embedded in processes of policy learning and broader sets of urban development goals.

\section{Methods}

This research involved document analysis and interviews conducted with representatives from 20 cities in Fall 2019. We identified 58 U.S. cities engaged in planning for AVs. The Bloomberg Philanthropies "AVs in Cities" online observatory served as a starting point (Bloomberg Philanthropies, 2019), which as of August 2019 included 53 U.S. cities. Upon closer examination, we excluded several due to little or no information about the project, but then added other cities that had known AV planning activities to reach a final sample of 58 cities. The final sample includes cities that range in size from 10,000 to 8.5 million residents and with numerous actors and stakeholders involved in the planning and deployment of AVs: city governments, regional planning agencies, transit agencies, universities, state departments of transportation, and the private business sector. 


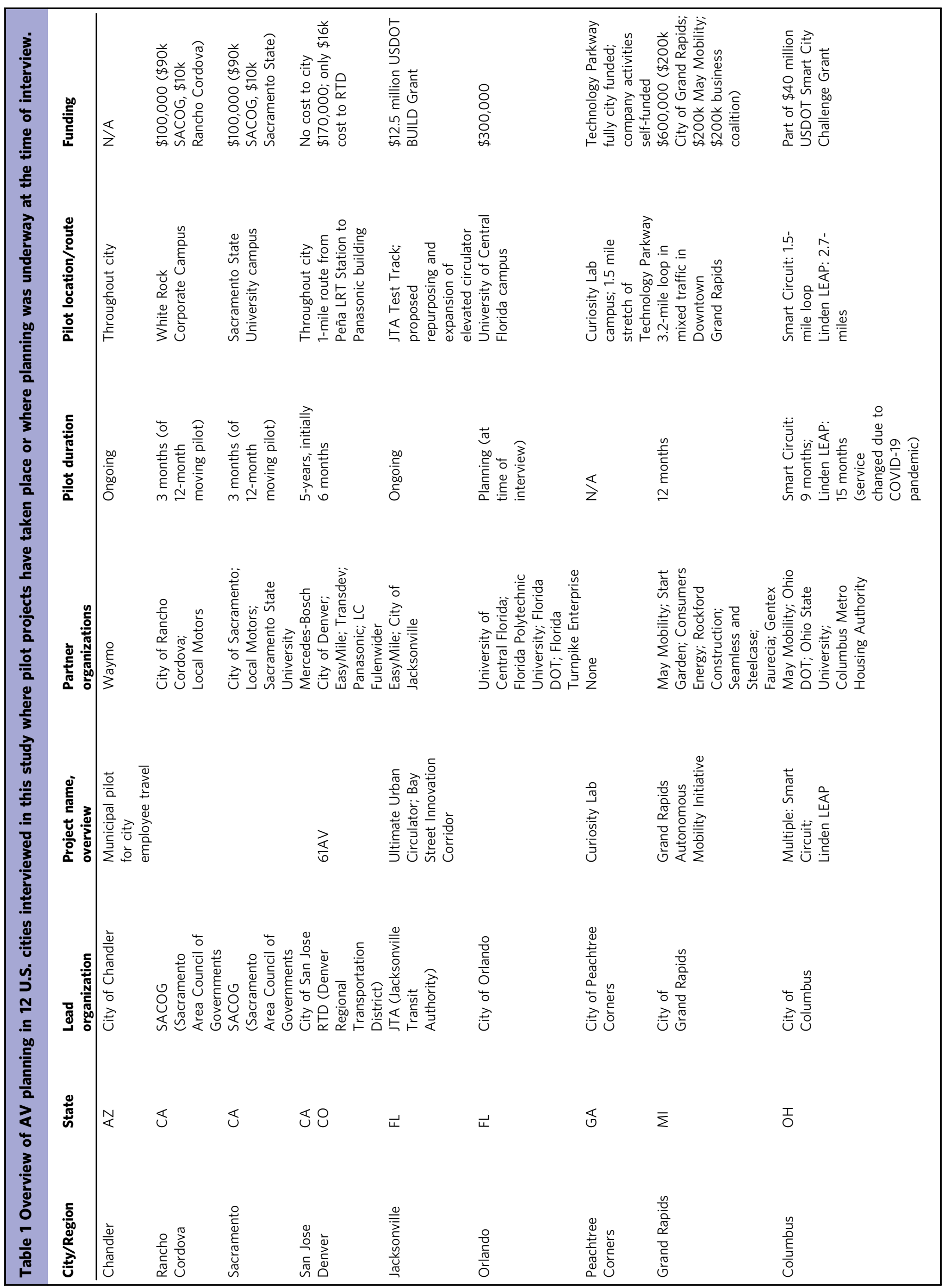




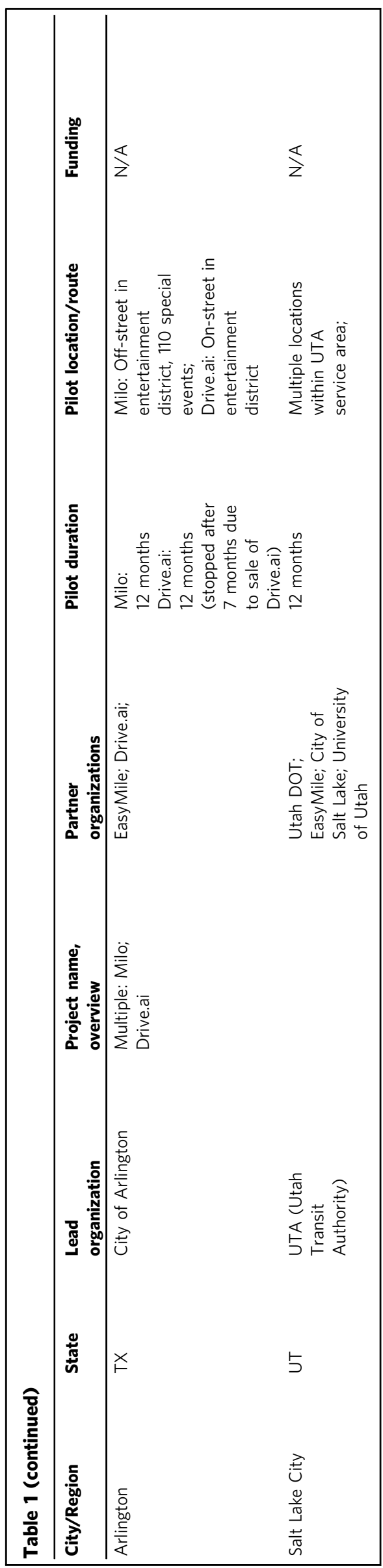

Throughout our analysis we use the term 'city' to denote this range of actors involved in various aspects of decision-making in specific places. Our initial intent was to only focus on municipal governments, but upon a more nuanced assessment of AV projects, limiting our research to only those places where municipalities took a leading role in AV deployment would have resulted in a much smaller sample and missed on a lot of the complexity involved in these projects. The nature of new partnerships and ways of planning for AVs blurs traditional lines between city and regional government and planning agencies and between public and private. Therefore, the 'city' as a unit of analysis is less precise but serves as a useful reference to a place and the actors involved in planning for AVs in that place.

Our initial research included document and plan analysis for each of the 58 cities to understand the types of activities in which cities are engaged. This included reviews of city websites, transportation plans, comprehensive planning documents, request for proposals (RFP), and media, press releases, and blog posts. In many cases, media accounts were the only documents we could identify that detailed an AV project. This analysis shows that the activities that cities are engaged in four distinct areas, currently with little overlap: (1) regulation, (2) testing, (3) planning, and (4) piloting. We found that cities using pilot projects are the largest category, with 27 out of 58 cities using this strategy. This prompted us to explore in greater detail how exactly cities were using pilot projects to plan for an AV future that address the transportation challenges they face.

The document analysis was supplemented through interviews with selected city officials. We contacted staff in each of the cities who were listed as points-of-contact for AV planning (if such a person was listed). Alternatively, we emailed planning or transportation directors who identify relevant staff to interview. Many of these staff were within city transportation departments, but others were in departments for innovation or emerging technology, public works, or economic development. Other organizations we interviewed included local or regional transit agencies, regional planning organizations, and state departments of transportation. In two cases, we were also able to interview industry partners who worked with the city to develop their pilot projects. In total, we conducted 24 interviews with experts in 20 cities. The study and interview protocol were approved by the Arizona State University (Tempe, Arizona) Institutional Review Board (IRB) and all interview participants gave informed consent to participate in the interviews.

There are four parts to the interviews: (1) background, including who initiated the pilot (or policy), when it ran, and obstacles faced; (2) the structure of the project, including any partnerships and how it fits within the broader planning context; (3) the goals and objectives of the pilot (or policy) and how they relate to broader community and transportation goals; and (4) how they are assessing their efforts. Questions varied slightly if a city's efforts focused on a pilot project or a policy initiative/regulation, but the goals were the same-to understand how current efforts are intended to guide future planning and deployment of AVs. To analyze the interviews, we transcribed them and conducted content analysis to identify key themes that emerged.

Tables 1 and 2 provide an overview of some key characteristics of the pilot projects and planning activities, including who initiated the project, partner organizations, duration of the pilots, location and route, and funding (if available). This overview shows that there is significant variation in pilot projects, particularly in terms of duration, location and length of route, partnership structures, and funding.

In the section that follows, we present our main findings as five key lessons and combine this with a discussion of the implications for urban planning and transportation policy for each one which 
ARTICLE

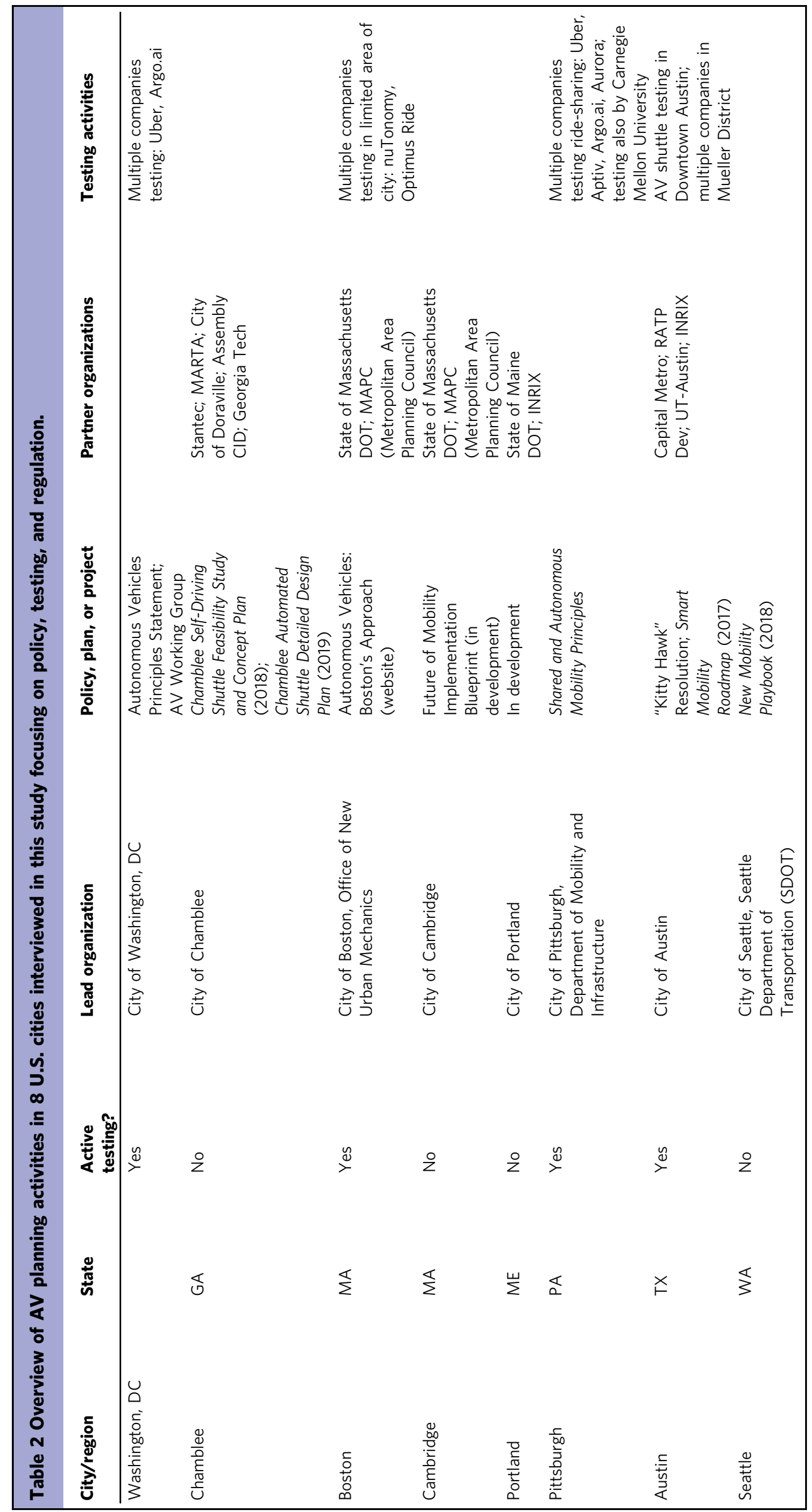

HUMANITIES AND SOCIAL SCIENCES COMMUNICATIONS | (2021)8:325 | https://doi.org/10.1057/s41599-021-01006-2

7 
Table 3 Overview of key research findings.

\begin{tabular}{|c|c|c|}
\hline & Thematic area & Overview \\
\hline 1 & Pilot goals & $\begin{array}{l}\text { These is a disconnect between the goals of the } A V \text { pilot projects and a city's transportation goals. Those interviewed cite the } \\
\text { ways in which AVs might help cities, but pilot projects rarely directly address these challenges. AV pilot goals, however, } \\
\text { focus on introducing AV technology to the public, exploring the feasibility for public transit, identifying infrastructure needs, } \\
\text { and promoting economic development. Many of the goals benefit AV companies more than they benefit cities. }\end{array}$ \\
\hline 2 & Long-term planning & $\begin{array}{l}\text { Most of the cities interviewed lack a long-term vision of how AVs fit into their future mobility systems and how they might } \\
\text { address transportation goals the city already has. Few cities have yet incorporated AVs into their long-term transportation } \\
\text { plans, but some have begun creating stand-alone documents addressing AVs and new mobility, particularly those where AVs } \\
\text { have not yet arrived or where they are limited to testing. }\end{array}$ \\
\hline 4 & Policy learning & $\begin{array}{l}\text { Evaluation of AV pilot projects is limited. What is done is often only of value to the technology company whose vehicles were } \\
\text { used. What is learned is less relevant for cities trying to use pilot projects to develop future policies for AV deployment. }\end{array}$ \\
\hline 5 & Public benefit & $\begin{array}{l}\text { In nearly all cities included in our analysis, there is a general sense that an AV pilot should provide some public benefit, but } \\
\text { what this is and how to get it remains elusive. Cities fail to ask what it is they are getting from the pilot project and who is } \\
\text { benefiting. In general, the benefits are mainly realized by the AV companies, not by cities. }\end{array}$ \\
\hline
\end{tabular}

emerged through our thematic analysis. The findings presented in this paper focus on the efforts of the 20 cities where we interviewed those working on planning for and deploying AVs. These cities provide a mix of experiences with pilot projects, from those that have completed one or multiple pilots, to those that were conducting or planning to in the near-term, and even those that intended to explore the viability of using pilots to help inform public policy.

\section{Lessons learned from AV pilot projects: findings and discussion}

Through our thematic analysis of the interviews and document analysis we have identified five key features of current approaches to AV pilot projects, which are making them less effective as tools for urban and transportation planning and policy. These are summarized in Table 3. The five points discussed are highly interrelated and while a few notable cases seem to indicate that the way these pilots are being conducted is changing, not enough cities are moving this this direction.

Pilot goals versus transportation goals. Our first key finding is that there is a strong disconnect between a city's transportation goals and the goals of the pilot projects being conducted. In general, all interviewees discussed common transportation goals shared by nearly all cities. Within the interviews, this included goals such as improving safety (12 cities), reducing congestion (13 cities), increasing mobility for disabled and elderly populations ( 5 cities), and reducing parking requirements and providing opportunities for more compact urban development (2 cities). Several cities also cited other desired goals, such AVs contributing to a more equitable transportation system ( 5 cities) or increasing accessibility (3 cities) and increasing access to jobs (6 cities). These goals mentioned match up with those in transportation plans and comprehensive plans of cities interviewed, with the exception of investing in multimodal transportation and active transport (e.g., walking and biking). One of the main reasons we identify this as a noteworthy finding is the fact that those interviewed often believe that AVs will help them address transportation goals and that is justification for conducting a pilot project. When we analyzed what it is the pilots are doing, however, we see little connection to these transportation goals.

The most common goal of pilot projects was to introduce AV technology to the public. Many interviewees mentioned how public acceptance is one of the biggest barriers to AV adoption, which is supported by numerous surveys indicating that many people are not interested or willing to ride in an AV (Schoettle and Sivak, 2014; Bansal and Kockelman, 2017; Kassens-Noor et al., 2021). Nine of the cities we spoke with explicitly call this out as a reason for conducting an AV pilot project. In Jacksonville, FL, the regional transit agency, JTA, has a test track for AV shuttles. JTA uses this test track to engage with the public: "we actually leverage our test track for that community engagement piece. For example, if you were to come to the test track, we would take you for a ride and we would give you a survey... a big component of getting the technology deployed is socializing this with the public and this is part of our outreach (Interview 8, July 2019)." In Salt Lake City, in addition to rider feedback, UTA has also done extensive outreach with other governmental stakeholders in their region: "we had the Salt Lake City Transportation Department come out. We did an elected official invitation when we kicked off the pilot. We invited all the mayors, the governor, and lieutenant governor, and we did a media day. So that was kind of like the top-level event. And then we've done stakeholder invites for our metropolitan planning organization. And also, we've involved the city's first responders, different fire and police groups (Interview 18, October 2019)."

Emphasizing this aspect of pilot projects makes sense since there is evidence that people who have ridden or have knowledge of AVs are more likely to view them positively. In a study of an AV shuttle pilot in Las Vegas, researchers found that "it appears that riding in a CAV helped enhance the understanding of many aspects of CAVs and could have been the reason shuttle riders felt more positive overall (Dennis et al., 2021, p. 19)." During the AV shuttle pilot in Grand Rapids, MI, the city conducted a survey of riders and generally found that "riders who felt negatively [about AVs] reflect a lack of understanding of the service or a lack of trust in the technology (City of Grand Rapids, 2019, p. 8)."

The most transportation related goal among these, feasibility within public transit, is primarily being pursued by transit agencies, not the cities themselves, though they are often a partner. Exploring this is not surprising, since this is a new technology that the industry generally argues will work seamlessly with existing transit and enable it to become more effective. Given this, cities and transit agencies are curious as to how AV shuttles fit into their transit ecosystems, and the potential benefits of AVs over traditional transit in terms of cost, safety, user satisfaction, etc. In Salt Lake City, the interest is in seeing how AV shuttles can improve transit service: "UTA is interested is around improving our transit service and filling in the gaps where it doesn't make sense or it's not feasible to run a full-sized bus and will never run 
a train. We're thinking of that last mile connection to, say, a research park, a corporate campus, maybe a college campus, maybe even, downtown where we could do circulator at low speed (Interview 18, October 2019).” In Denver, one of the goals of RTD was to "assess the viability of using an automated shuttle as part of their transit operations (Interview 6, July 2019).”

However, here we note another disconnect, in that many of the transit-oriented AV pilots are actually being conducted by cities that are not in charge of operating public transit. This poses significant challenges for a municipality in simply identifying goals for an $\mathrm{AV}$ pilot that is transit-oriented if this is not something the city actually does. In other words, what transportation reason is there for conducting an AV pilot? From a transit agency perspective, one of motivations in Jacksonville, FL for adopting AVs in transit is "increasing ridership... To drive folks more towards the public transportation and I think this (AVs) would be a conduit or enabler for that piece (Interview 8, July 2019)." But in most cases, from a municipal standpoint, the benefit is less clear, and this disconnect is one possible reason why the pilot goals diverge from a city's self-identified transportation goals and while it is a positive step that cities are at least curious about how AVs can help support public transit, it is less useful if they do not operate public transit systems themselves.

Two notable exceptions include Grand Rapids, MI and Arlington, TX. In Grand Rapids, the city is using AV shuttles to supplement its downtown circulator service. In this instance, the city being interested in understanding how well AVs might work within transit, asking questions like "is it cost effective? what does ridership look like? How does it work seasonally? How does it work in a whole bunch of different factors in the city (Interview 1, July 2019)?" makes sense. The city funds and operates its own free circulator, so finding ways to lower costs and possibly expand service is something they are very interested in.

In Arlington, TX, the city was interested in how AVs could help them "leapfrog" traditional transit: "our mayor was very vocal about his intention and what he called leapfrogging traditional public transportation service. He basically sees it as a positive in Arlington that had never invested in traditional transit so we're able to ride into more innovative approaches. Testing AVs was definitely part of that (Interview 16, September 2019)." Arlington is perhaps unique in that it currently does not have a traditional public transportation system, but the prospect of AVs is allowing them to consider innovative alternatives.

In addition to the two goals described above, other goals for AV pilot projects include: identifying possible use cases; identifying infrastructural needs; promoting economic development; developing guidelines and regulation and providing evidence-based policy; improving efficiency of city operations; and building institutional capacity within municipalities and other planning organizations; and learning about how the technology works. When compared against the list of goals for transportation, there is a clear mismatch. This is not to say these non-transportation goals are not important or useful, but as a transportation technology, it should be at least as important that AV pilot projects begin to address the transportation challenges cities think they can help them with.

These findings align with those of Steckler et al. (2020) who examined the goals of new mobility and AV pilots. What is interesting though, is that they find that other new mobility pilots (e.g., micro-mobility, TNC partnerships, and micro-transit) do address the transportation goals cities are interested in, which raises the important question of why AV pilots are not achieving this. Regardless, we agree with Steckler et al. (2020) and their conclusion that the most successful pilot program have clear goals or outcomes, and as our work shows, this more often includes non-transportation related goals. While transportation projects often aim to achieve broader societal goals, the AV pilot projects do not attempt to do this either, and remain more limited to the technical challenges that the technology continues to face before it can be more widely deployed. As AV technology matures, it will be important for cities and others to ensure that pilot projects and AV deployments move beyond these non-transportation goals and begin to address the real transportation challenges cities care about.

AV pilots without long-term plans. The second main finding of this work is that there is a general lack of long-term planning for AVs among the cities we interviewed. This manifests in two ways. First is that AVs are not included in long-range planning documents. Second is not planning for what comes next beyond the immediate pilot projects they are conducting.

In the first instance, out of the 20 cities we interviewed, only nine of them include any mention of AVs in either their longrange transportation plans or their general plans. Moreover, a majority of these only include AVs as a passing mention and others advancing policies related to creating policy and regulation that will help them prepare for technology-driven disruptions, of which AVs are one. Austin, TX perhaps includes the most policies with seven implementation actions related to AVs and emerging mobility solutions, which include outreach and education on AVs, regional coordination, AV research, and staff training in emerging mobility solutions (City of Austin, 2019, p. 281).

The age of some long-range plans means that AVs are not likely to be included in them, but in reviewing other planning documents, we see limited action. Again, Austin, TX is one notable exception, where there have been multiple pilot projects, which have informed the city's policy work and long-term planning. After a number of initial AV projects starting as early as 2014, the city developed the "Kitty Hawk Resolution", which outlines some of the broad goals the city has for AVs, which are detailed further in the Smart Mobility Roadmap (City of Austin, 2017). In 2019, the city released an updated strategic mobility plan, which incorporates AVs and discusses how emerging mobility technologies must be assessed in relationship to community needs and that new investment in infrastructure should enable adoption of emerging mobility technologies and AVs (City of Austin, 2019, p. 132-4). Seattle provides another case of stand-alone plans, with its New Mobility Playbook (SDOT, 2017), which includes goals, values, and policies for emerging technology and AVs.

Available funding is a major constraint on long-term planning for AVs. Most of the pilots examined in our study were initiated only after the city applied for and was awarded a grant, often a state or federal DOT grant. Our interviews suggest that cities do not typically have the resources or political will to conduct these AV pilot projects on their own, with their own money. Transportation grants and other funding enable cities to develop pilot projects, but only reinforce the fact that they are short-term and for a single project or deployment. As a result, once a pilot project ends, unless the city has secured additional grant funding, it can no longer continue its work on AVs.

Alternatively, cities that have a financial stake in their pilot projects have a more long-term vision from the initial pilot. In Grand Rapids, MI, for example, the initial 12-month pilot project is funded equally by the City of Grand Rapids, May Mobility, and a consortium of businesses in the region, with each paying onethird of the $\$ 650,000$ cost of the initial pilot project. If successful, the city has plans to explore deploying $\mathrm{AV}$ shuttles out into neighborhoods to better connect them to Downtown and to continue their pilot projects and test the technology in different contexts: "it allows us to actually look and see is this good in a 
dense urban area or does it make more sense and more like a suburban area? What are the different business cases for it (Interview 1, July 2019)?” In fact in summer 2021, the City of Grand Rapids launched an on-demand service using the AV shuttles in addition to continuing its use of the shuttles in the downtown core (City of Grand Rapids, 2021).

The interviews and document analysis show that cities conducting pilot projects do not have a firm grasp of what AVs can offer. Like Freemark et al. (2019), we find that those cities that are more likely to cite possible negative impacts are more likely to be developing regulation and creating a long-term vision of what AVs might be able to help them with, as is the case in cities like Pittsburgh, Boston, and Seattle. In Sacramento, one of focus areas with their work around AVs is on ensuring that they learn from the projects they develop and use that to "inform regulation moving forward (Interview 19, November 2019)" at the state level and in partnership with other large cities in California. One of the key points in this case is that AVs need to be regulated in some way to work towards achieving the city's transportation goals, but that regulation also should not put up unnecessary barriers to innovation in the AV space. This is summed up in Washington, DC where the city's "goal is to learn about the technology and regulate it early on so that if something is problematic that the industry isn't seeing regulations that are new and look punitive and reactive (Interview 11, August 2019).” In this way, developing guidelines and regulating is a proactive step and means having open conversations and developing partnerships early in the process. Planning efforts like these are more likely to result in outcomes that have more benefit to the overall sustainability and equity of the transportation system.

Emphasis on economic development benefits. As mentioned above, the majority of AV pilot programs have goals relating to non-transportation goals. Among these, goals around economic development represent an interesting trend that is worth discussing further. Within the area of economic development, there are multiple ways in which cities frame their AV pilots to directly and indirectly support economic development goals over transportation goals. In most cases, we see this occurring in places that are not focused on regulation of AV technology, and instead view regulation as a possible barrier to innovation. Ferreira et al. (2020) frame this as a pro-innovation bias in which new innovations and technologies must be rapidly adopted or experimented without a public debate on their purposes, risks or benefits, and it is assumed that these technologies are delivering benefits.

Several cities interviewed showed interest in being an early adopter or "hot-spot" for AV innovation and three cities cited economic development as a direct goal of their pilot projects. In Jacksonville, the choice to pursue AV shuttles over other possible transportation solutions was due to its innovative nature: "Granted there could be other means, right, and I'm not saying that those aren't the right way as well, but I think this is an innovative way to further expand the service that we're providing to the community (Interview 8, July 2019)." Likewise, in Arlington, TX, being innovative was directly linked to a reason why the city did an AV pilot: "We're also very much interested in looking at where other more sustainable ways to move people around. So, I think that the AV testing, you know, part of it definitely was with the city wanting this... wanting to be the first as the innovative transportation leader. However, then I think it was really all about, what are the conditions of the technology? And where would it make sense for it to be deployed? (Interview 16, September 2019)."
This positive evaluation based on the presumption that AVs will deliver immediate benefits without a structured assessment process can be understood as "maladaptive planning". Ferreira et al. (2020) describe this as the process when policy-makers, funding agencies, planners, and other relevant political stakeholders insists on proliferating and then positively assessing, implementing, and disseminating initiatives that they have too little rapport with and that are not fit for the challenges being experienced in the social, economic and natural environments.

This approach of being an innovative and being a leader in the AV space can be linked to broader ways in which cities market and brand themselves. This is a well-established way in which cities go about economic development (Shaw and Montana, 2016), particularly in efforts to attract creative and technology sector workers (Florida, 2014). Research has also shown that public transit projects are often sold to the public and to decision makes for their economic development potential instead of their transportation benefits, which is particularly true in modern streetcar systems (Higgins and Kanaroglou, 2016; Brown and Mendez, 2018). When thinking beyond the costs associated with light rail or streetcar infrastructure, AVs are an innovative solution that cities believe will brand them as innovative and technology oriented, while also still supporting public transportation. This is explained when observing how cities might be trapped in an innovation imperative, where addressing challenges is evaluated in terms of rapid experimentation of new technologies for the sake of experimenting without intentional planning (Ferreira et al., 2020) and instead framing policy problems in terms of innovation (Pfotenhauer et al., 2019).

Other cities are much more direct in the ways they promote economic development. For example, in Chandler, AZ, their efforts around AVs directly speak to this goal of economic development: "we're looking at it from an economic development perspective. How can our support of this immature industry, growing industry, help advance future economic competitiveness of the city? Automotive tech is one of our target industry clusters, so it was a natural fit to see how this can elevate Chandler's reputation within the state (Interview 24, November 2019)."

In Peachtree Corners, GA, the city has developed Curiosity Lab, which serves as a smart technology incubator. Part of their investment in this has been to build a 1.5-mile smart roadway, complete with $5 \mathrm{G}$ sensors and connected and smart infrastructure, as a way to attract AV companies to their city to test and develop their technology in the real-world. This does not operate like many of the other pilots being done, in that any company is able to come to the innovation lab and use the facilities. When interviewed, Local Motors was testing vehicles along the smart roadway while also giving rides to the public, which was not a requirement of the city. According to the city, this investment in their smart technology incubator is already having the desired effect: "we are already seeing this paying dividends. So, we're like, look, if we make it really enticing for companies to come use the facility, we will generate activity, we'll increase activity. Well that activity is going to indirectly benefit the city... We have already had buildings that had been unoccupied, that have now been occupied because the company was considering a bunch of places to go, but then they saw this going in and they're like, we want to be there, we want to be in that space. We want to be where all this synergy is. So, we've had jobs already get created or moved to our municipality because of this amenity, even though we haven't charged for its use (Interview 20, November 2019)."

In these two instances, the cities are very clear in their intent of capitalizing on the nascent AV industry in hopes of creating an economic cluster of businesses and expertize. They, like other cities seeking to attract businesses, are investing in infrastructure and providing incentives for companies to relocate to their 
municipalities. While creating jobs is an important objective, using an emerging technology, such as AVs, with limited considerations of the benefits and risks to the community and without their consent, could have significant repercussions. Wiig (2015) points out that smart city scholarship often critiques the role of the tech industry in shaping smart city policies, but more attention needs to be drawn to understand why cities seek smart city policies with industry. Cities seeking economic benefits and smart city partnerships likely see the process of developing projects as producing results. However, this overemphasis on innovation as an economic development paradigm supersedes the ability of alternative values and visions for the future (von Schönfeld and Ferreira, 2021).

A lack of learning from AV pilots. A pilot project is intended to help understand how a specific technology or intervention helps achieve a specified outcome. A key aspect of a pilot project is the intention to scale up or expand the intervention. Expansion is defined as the type of scaling that happens when the pilot project is not closed or dissolved but is rather expanded with new partners or users to the project, or by enlarging the geographical area in which the project operates (van Winden and van den Buuse, 2017). If the initial intervention is not successful in achieving what it was meant to, it can be adjusted and refined based on a continual process of learning to see if the desired outcome is achieved. The limited timeframe of the AV pilot projects we analyzed, due in large part to how they are funded, pose significant limitations on the ability of these projects to function like true pilot projects. However, we also see limitations in the effectiveness of current AV pilots due to a lack of general evaluation and the fact that what cities are learning from their pilots do not assess how well AVs help a municipality or transit agency meet its goals around transportation.

When looking at whether there is any sort of evaluation, only half of cities that have a completed or ongoing pilot have an official summary report or some sort of project summary. The reports provide some basic details about the pilot projects, discussing ridership and providing a few key findings from the rider surveys they conducted. This is a higher percent of pilot projects than Steckler et al. (2020) found when looking at new mobility in general, in which they found that only $11 \%$ of projects conducted assessments. The fact that as many as $50 \%$ of $\mathrm{AV}$ shuttle pilots are producing such assessments is a positive trend.

However, when we examine what cities are learning from the AV pilots, we see that most of the information collected does not address transportation challenges, but instead emphasizes the operations conditions of vehicles and rider perceptions. This is in line with what others have found as well (Steckler et al., 2020; Mahmoodi Nesheli et al., 2021). In all cases we examined, ridership was a key metric that cities collected data on. In Denver, RTD was interested in issues around vehicle reliability, battery performance, on-time performance (Interview 6, July 2019). Likewise, in Salt Lake City, UTA is provided with daily reports on operational data: "There's a ton of operational data and we get daily reports about the vehicle like performance, how many stops it had, its average speed, battery usage, ridership, ramp deployment... weather factors, any safety issues... percent of the time that it's operated autonomously (Interview 18, October 2019)." This information is useful for thinking about costs and understanding how well AVs work operationally, but at this early stage of development, this information is more relevant to a testing phase than a pilot phase concerned with solving transportation problems.

One aspect of learning that interviewees discussed was on the relationship between AV pilots and policy. In instances where pilots were being conducted with limited policy prior, cities connected the pilot project to aid the development of policy. Likewise cities that had a more policy-oriented focus hoped that eventual pilot projects would help them refine policy to better support their transportation goals. In San Jose, for example, the city's focus is on attempting to inform state and federal regulation and using their pilots to do that: "cities going out and regulating only continues to make this not scalable in a lot of ways when companies have to do different things. So, we took the approach that as a city, we really want to have good state regulations and good federal regulations, not necessarily get into a whole bunch of piecemeal regulation for autonomous technology. We'd rather be a good partner in this space and glean those insights to shape the deployment around our transportation goals. In order to do that, you have to be a good partner (Interview 17, October 2019).” In this instance, the city intends to use what they learn from various stages of their pilot project to inform regulation moving forward.

However, for most cities, the link between policy and pilots is uncertain. Even cities that already have policies are uncertain how to link pilot projects and the learning from them to future policy. Moreover, in places where learning has occurred, it has mostly informed future pilot deployments and not necessarily broader transportation solutions, as was the case in places like Arlington, TX. We attribute this uncertain connection between pilots and policy to the lack of existing planning and policy for AVs in existing transportation planning documents. This is due to both the newness of the technology and the slow rate at which planning documents are updated, as well as the continued uncertainty around what impacts AVs will have. These factors are why transportation goals within AV pilot projects are ill-defined and why the learning that happens during a pilot project generally doesn't address transportation challenges or help identify future policy and regulatory needs.

The continued lack of learning that we see from AV pilot projects, from one to the next project in the same city or between different cities, raises important questions about why they continue to be deployed. Shove and Walker (2007) caution against the excessive levels of managerialism and social engineering that we are exposed to, of which AV pilot projects can be understood as a tool for achieving this. In many ways, the goals of many pilot projects are introducing the technology to the public and slowly get them used to it. As one interviewee stated, an important aspect of their work was rooted in the "social engineering aspect" and "how do we create an effective strategy to socialize this technology? Where folks become comfortable with getting in a vehicle without a driver (Interview 8, July 2019)."

This managerial and piecemeal approach used within AV pilots, however, is resulting in what Savini and Bertolini (2019) call marginalization, or a cycle of permanent experiments. Projects exist "in a permanent temporariness (p. 840)." They argue that this marginalization happens when there is depoliticization of the transformative potential of a project or technology. In the case of AVs, we see this occurring to the extent that pilot projects are filling niche environments and are being continuously deployed with little or no public engagement and limited to no public debate about alternative futures or ways of using AV technology.

Not maximizing public benefit. Our final finding is that cities are not maximizing the potential public benefits from pilot projects. Cities fail to ask what the city is getting from this pilot project and who benefits. This issue of public benefit and public value is important since cities are using public resources to fund these pilot projects. Although many cities discuss partnerships with AV companies-a key elements of AV planning that has 
been promoted to better leverage public value (e.g., Henaghan et al., 2018; AMPO, 2019; Miller and McAslan, 2019)—one-third of the cities we interviewed used a traditional RFP process and/or procurement process in which they found a vendor (an AV company to provide the vehicle and technology) to provide a service (the AV pilot), and in some cases, city staff were the ones trained to actually operate the vehicles during the pilot. This issue of public benefit, manifests in several ways, from how partnerships are formed and what is shared within the partnership, but also what the outcomes of the pilot projects are and how these related to potential public benefits.

In nearly all our interviews, respondents were very interested in data, particularly the new types of data that AVs make available from their array of sensors. However, when asked what kind of data-sharing agreements were in place, these were limited to the very general operating conditions of the vehicles and in many cases no data-sharing agreements existed at all. Among all but one city, we attribute this to a lack of thinking beyond the pilot project and not connecting the pilot and the data collected by vehicles to other transportation goals and not leveraging these mobility partnerships.

As the exception, San Jose stood out in their approach to a partnership with Mercedes and in addition to leveraging the pilots and partnership to cost the city nothing, they were keen to think about how the city could leverage some of the new types of data that AVs generate from its sensors, beyond just the basics of ridership and vehicle performance. San Jose's perspective is that only collecting this data is a "missed opportunity": "one of the really rich pieces of information that you can get is the anomalies and specifically midblock pedestrian crossing. You now have a moving IoT device that is traveling the same route over and over all day. You can provide a heat map that indicates how often are people crossing in this area all the time. You can go study the location and make an infrastructure decision to make it safer. Really those are the types of things that we were really interested in taking a look at (Interview 17, October 2019)." In this way they city is seeking ways to use data collected by AVs during the various pilot phases to help guide current transportation planning decision and to make their roads safer.

Generally, cities are aware of the AVs' capacity to collect data, but unclear on what these data could be useful for or what should not be collected. The pilot projects studied show AV companies collecting data with their vehicles about how they operate in realworld conditions and using that information to further develop their technology. Since cities pay to conduct these pilot projects and receive little transportation benefit, they are essentially paying for AV companies to continue research and development. Going forward, it is important for cities to think about new mobility partnerships and to develop new approaches to working with mobility companies, as is the case in Grand Rapids or San Jose. Without these new types of partnerships, public benefits will likely remain limited.

We also see the issue of public value become relevant in discussions about investment in infrastructure. In our interviews, a common goal of cities with $\mathrm{AV}$ pilots was to identify infrastructural needs to guide public investment in ways that it would not be wasted. By working together with the AV companies, a handful of cities hope to identify some of these needs and make smarter long-term infrastructure investment and remain a leader/early adopter of AVs. However, this also presents the challenge for cities as they are required to plan in an era of rapid technological change, where an investment in one technology quickly becomes obsolete. This is evident in Grand Rapids, where the city has installed over 200 DSRC units at intersections and was interested in having their AV pilot tie into this connected infrastructure. "The new startups and Ford and they don't want the DSRC standard they want the $5 \mathrm{G}$ standard; and so we're kind of left in a little bit of a holding pattern because we don't want to invest a ton of money and put in DSRC roadside units at our intersections throughout the city... We would have preferred that they would have used it [the roadside controllers] because a lot of it is actually already available at some of the intersections along the route... They're more kind of waiting on the same thing-they are more focused on camera technology that actually visualizes the intersection (Interview 1, July 2019)."

In Jacksonville, FL, the JTA is looking at ways to repurpose existing infrastructure-their elevated downtown monorail system-and use it to provide a dedicated roadway for AV shuttles that would circulate through downtown and connect surrounding neighborhoods. Another component of the work in Jacksonville is the Bay Jax Innovation Corridor (North Florida TPO, 2019), which is a three-mile stretch of road through the urban core where AVs will eventually be deployed. Also in this corridor, "the city is also introducing smart censors and some of those smart region capabilities (Interview 8, July 2019)" to pilot on a small scale the types of technologies that may eventually be deployed at scale with AV shuttles.

These cases show the tensions between cities that are trying to ensure that public investments are fully utilized, while doing so in an environment of rapidly changing technology. It also reiterates the question of who benefits. If a city spends public money on infrastructure that is then primarily used to benefit private companies that provide a transportation service (e.g., a fleet of on-demand AVs), is that generating public value? Numerous critics of smart cities argue that these projects fail to deliver public benefit because they are working against the public interest (Wiig, 2015; Goodman and Powles, 2019). In their analysis of Sidewalk Lab's failed smart city project in Toronto, Goodman and Powles (2019) emphasize that the basic structure of the project was set up to "fundamentally disempower the public and serve the interests of the private company (p. 497.)" Similarly, we find that AV pilot projects heavily serve to benefit the companies and thus limit the ability of them to provide public benefits that urban and transportation planners believe they will.

\section{Conclusion}

The enthusiasm for AVs as a potentially transformative transport technology is dampened by the approaches cities have taken with pilot projects. The prevalent features of current approaches to AV pilot projects identified through the analysis presented in this paper pose significant challenges for cities as they attempt to plan for AVs and other emerging technologies. These approaches indicate that cities remain constrained by the past in their thinking and their ability to plan. While many of our interviewees indicated that AVs may offer significant opportunities for their jurisdiction to improve its transportation systems, increase accessibility and equity, or promote sustainable transportation solutions, there is little evidence to show that cities are moving towards a proactive planning approach rather than a reactive one in terms of developing a new vision of an automated transport future. In many ways, this is further evidence of what Bina et al. (2020) call the 'colonization of urban futures'. In the case of AVs, many cities remain too busy reacting to the not yet realized promises of industry to imagine their own alternative urban mobility futures.

Since AV technology is both unproven and rapidly developing, it is not surprising that cities are somewhat cautious in their approaches. In the absence of significant state and federal regulation and legislation, city planners and municipal decision makers have a huge opportunity to shape the discourse around AVs and many cities do recognize this opportunity, with some seeing pilot projects helping to shape that discourse. This 
however is being done without recognizing the ways in which they are being influenced by AV industry interests. Additionally, the evidence collected through this research suggests that conventional planning processes may inhibit creative applications of AV technology. Rather than allowing cities to leverage emerging technology, current approaches of AV pilots may further entrench automobility (Dowling and McGuirk, 2020). More pressing, however, is that AVs are not yet incorporated into the long-range planning process, and many of the expected benefits are tangential to the transport benefits of improved services and lower operating costs. Moreover, while economic development and other benefits are often included in the rationale for transportation projects, this rationale is enhanced in the current ways in which AVs are promoted, a link which shows how intwined within smart city thinking this technology is. The capacity of cities to undertake long-term planning is significant and if used to help shape AV discourse and to guide their deployment in socially beneficial ways, it could remain a powerful tool. Taking more engaged, deliberative, and anticipatory approaches (Cohen et al., 2018; Cohen and Cavoli, 2019; Buhmann and Fieseler, 2021) towards the automation of mobility within long-range transportation planning will also be highly beneficial.

The critiques of the current planning approaches to AVs in cities in the U.S. presented in this paper echo numerous critiques of smart cities and the increasing ways in which innovative and disruptive technologies are promised as a cure-all for urban problems. These "smart" solutions are often less coherent than they appear to outside observers (Kitchin, 2015) and that smart city approaches are led by industry and imposed on cities and prevent them from imaging alternative futures (Bina et al., 2020; Miller, 2020). The ways in which AV pilot projects are presently constructed highlights the "techno-solutionism" that rationalizes these projects on the basis on their ability to solve complex and long-standing transportation challenges, but in practice, they do little to advance these benefits. This approach assumes that a technological fix to urban problems-in the case of AVs, transportation challenges - can be done with limited input from the public (Vanolo, 2014; Calzada and Cobo, 2015), which raises important questions about whose future is being pursued through the application of AV pilot projects-or as Cugurullo (2018) puts it, "smart for what and for whom? (p.121)". Our research has shown that although cities frequently discuss using AVs to solve their own long-standing transportation problems or to encourage economic development, AV pilot projects still overwhelmingly benefit those developing the technology. As with other smart city solutions, cities pursuing AV pilot projects have been convinced by industry that this is what they need to do to adequately plan for this emerging technology. In this way, AVs continue to contribute to the making of the smart city, whereby the city is transformed into a marketplace for new technologies, instead of a place where markets operate (Clark, 2020; Kitchin, 2021).

This research also points to the fact that those cities where AV pilot projects have yet been deployed or where companies remain limited to testing only, seem to be taking a different route. These cities remain more skeptical of the technology, in general, and have also been places at the forefront of rethinking what the smart city is - particularly places like Portland, OR and Boston, MA. However, the ability of these alternative approaches to AVs, and smart city technologies more broadly, remain isolated and the exception, and the extent to which they could influence policy and thinking where the industry-led imaginary of an automated mobility future has already begun to take hold is yet to be seen, and an area where more work must be done.

As a first step to overcome the industry-led approaches currently dominating the $\mathrm{AV}$ landscape, cities can pursue more engaged approaches, first incorporating broad visions and goals for AVs into their long-range transportation plans (either in stand-alone plans or in forthcoming major plan updates). This would allow citizens to take back some of the power to decide what type of future they want for their communities. We also see ways that current approaches to AV pilot projects can be improved to maximize benefits to municipalities and transit agencies and for cities to take a more active role in the process. Most pressing for cities considering AV pilots is to set up more robust processes for learning from them that more directly linked the projects to goals the city has and not what an AV technology provider needs. Pilot projects can be sources of data and other information about how interventions perform, or even provide data that helps solve pressing urban problems that exist now. However, in the case of AVs, evaluation presently lacks the systematic approaches to analysis that are hallmarks of research and learning.

The absence of AV planning in long-range transport plans, and the vague promises of economic development from $\mathrm{AVs}$, leaves concerns that cities are ill-equipped to evaluate and improve these projects for future development in a way that is likely to result in a more sustainable and equitable transportation system than we currently have. Although it is possible that cities will learn how to evaluate these projects as more are deployed, and to incrementally improve the outcomes, the experience of other 'smart' urban technologies-and the solutions they promise-suggests that this is less likely. Additionally, an overreliance on an incremental approach that uses piecemeal pilot projects is more likely to result in a slow transition to an automated future whereby citizens are slowly introduced to the technology and less likely to object-a scenario likely favored by the AV industry. This approach with limited learning will delay more important and meaningful conversations about the future role of AVs in our cities and likely prevent a more transformative use of the technology (or by other means). Cities cannot idly sit by and wait for the technology to arrive, nor can they be swept up in the promise of AVs being a magic bullet solve their problems. Both approaches, demonstrated by the cities we have interviewed give technology companies an upper hand. It is time cities realize that the AV industry needs cities a lot more than cities need AVs and that in this realization there lies huge opportunity and potential for cities to lead the way and not blindly follow.

\section{Data availability}

The datasets generated in this study are not publicly available due to the privacy agreement between the authors and the interviewees, as required by the Arizona State University Institutional Review Board. Upon reasonable request, anonymized data are available from the corresponding author. Documents analyzed in this study are publicly available online and a list of these can be made available upon request from the corresponding author.

Received: 30 June 2021; Accepted: 26 November 2021; Published online: 14 December 2021

\section{References}

Acheampong RA, Cugurullo F, Gueriau M, Dusparic I (2021) Can autonomous vehicles enable sustainable mobility in future cities? Insights and policy challenges from user preferences over different urban transport options. Cities 112 (May). https://doi.org/10.1016/j.cities.2021.103134

Adler MW, Peer S, Sinozic T (2019) Autonomous, connected, electric shared vehicles (ACES) and public finance: an explorative analysis. Transportation research interdisciplinary perspectives 2 (Sept). https://doi.org/10.1016/ j.trip.2019.100038

AMPO. 2019. National Framework for Regional Vehicle Connectivity and Automation Planning. http://www.ampo.org/wp-content/uploads/2019/04/2019 AMPO-Framework-11.pdf. Accessed 15 Oct 2019 
Angelidou M (2015) Smart cities: a conjuncture of four forces. Cities 47(September):95-106. https://doi.org/10.1016/j.cities.2015.05.004

Bailey DE, Erickson I (2019) Selling AI: the case of fully autonomous vehicles. Issue Sci Technol 35(3):57-61. https://issues.org/selling-ai-the-case-of-fullyautonomous-vehicles/

Bansal P, Kockelman KM (2017) Forecasting Americans' long-term adoption of connected and autonomous vehicle technologies. Transp Res Part A: Policy Pract 95(Jan):49-63. https://doi.org/10.1016/j.tra.2016.10.013

Bina O, Inch A, Pereira L (2020) Beyond techno-utopia and its discontents: on the role of utopianism and speculative fiction in shaping alternatives to the smart city imaginary. Futures 115 (Jan). https://doi.org/10.1016/ j.futures.2019.102475

Bissell D (2018) Automation interrupted: how autonomous vehicle accidents transform the material politics of automation. Polit Geogr 65(Jul):57-66. https://doi.org/10.1016/j.polgeo.2018.05.003

Bloomberg Philanthropies. 2019. Autonomous vehicles in cities. 2019. https:// avsincities.bloomberg.org. Accessed 05 Dec 2019

Brown A, Rodriguez G, Hoang T (2018) Federal, state, and local governance of automated vehicles. https://policyinstitute.ucdavis.edu/wp-content/uploads/ AV-Governance_IssuePaper_1218.pdf. Accessed 10 Sept 2019

Brown J, Mendez J (2018) Examining the development effects of modern-era streetcars: an assessment of Portland and Seattle. https://transweb.sjsu.edu/ sites/default/files/1798-Brown-Development-Effect-Streetcars.pdf. Accessed 22 Jun 2021

Buhmann A, Fieseler C (2021) Towards a deliberative framework for responsible innovation in artificial intelligence. Technol Soc 64 (Feb). https://doi.org/ 10.1016/j.techsoc.2020.101475

Bulkeley H, Castán Broto V (2013) Government by experiment? global cities and the governing of climate change. Transp Instit Br Geogr 38(3):361-375. https://doi.org/10.1111/j.1475-5661.2012.00535.x

Bulkeley H, Coenen L, Frantzeskaki N, Hartmann C, Kronsell A, Mai L, Marvin S, McCormick K, van Steenbergen F, Voytenko Palgan Y (2016) Urban living labs: governing urban sustainability transitions. Curr Opin Environ Sustain 22(Oct):13-17. https://doi.org/10.1016/j.cosust.2017.02.003

Bulkeley H, Marvin S, Voytenko Palgan Y, McCormick K, Breitfuss-Loidl M, Mai L, von Wirth T, Frantzeskaki N (2019) Urban living laboratories: conducting the experimental city? Eur Urban Region Stud 26(4):317-335. https://doi.org/ $10.1177 / 0969776418787222$

van den Buuse D, van Winden W, Schrama W (2021) Balancing exploration and exploitation in sustainable urban innovation: an ambidexterity perspective toward smart cities. J Urban Technol 28(1-2):175-197. https://doi.org/ $10.1080 / 10630732.2020 .1835048$

Calzada I, Cobo C (2015) Unplugging: deconstructing the smart city. J Urban Technol 22(1):23-43. https://doi.org/10.1080/10630732.2014.971535

Chase R (2014) Will a world of driverless cars be heaven or hell? CityLab 03 Apr. https://www.citylab.com/transportation/2014/04/will-world-driverless-carsbe-heaven-or-hell/8784/. Accessed 22 June 2021

Chatman DG, Moran ME (2019) Autonomous Vehicles in the United States: Understanding Why and How Citiesand Regions Are Responding. https:// doi.org/10.7922/G2CZ35DZ. Accessed 11 Sept 2019

City of Austin (2017) Smart mobility roadmap. Austin TX. https://austintexas.gov/ sites/default/files/files/Smart_Mobility_Roadmap_Executive_Summary__Final_with_Cover.pdf. Accessed 24 Apr 2019

City of Austin (2019) Austin strategic mobility plan. Austin TX. https:// app.box.com/s/7aiksxmwwgymalsty0lm21wingk0slug. Accessed $25 \mathrm{Feb} 2020$

City of Grand Rapids (2019) AVGR and DASH rider survey summary. Grand Rapids MI. https://www.grandrapidsmi.gov/files/assets/public/departments/ mobile-gr/files/avgr-survey/avgr-dash-survey-report-022420-w-cover.pdf. Accessed 30 Apr 2021

City of Grand Rapids (2021) Grand rapids autonomous vehicle initiative \#AVGR. https://www.grandrapidsmi.gov/Government/Departments/Mobile-GR/ Grand-Rapids-Autonomous-Vehicle-Initiative. Accessed 30 Apr 2021

City of Pittsburgh (2019) Pittsburgh principles for autonomous vehicles. https:// pittsburghpa.gov/domi/autonomous-vehicles. Accessed 30 June 2019

City of Portland (2018) Smart automated vehicles initiative (SAVI). https:// www.portlandoregon.gov/transportation/73493. Accessed 30 June 2019

Clark J (2020) Uneven innovation: the work of smart cities. Columbia University Press, New York NY

Cohen T, Cavoli C (2019) Automated vehicles: exploring possible consequences of government (non)intervention for congestion and accessibility. Transp Rev 39(1):129-151. https://doi.org/10.1080/01441647.2018.1524401

Cohen T, Stilgoe J, Cavoli C (2018) Reframing the governance of automotive automation: insights from UK stakeholder workshops. J Respons Innov 5(3):257-279. https://doi.org/10.1080/23299460.2018.1495030

Creger H, Espino J, Sanchez AS (2019) Autonomous vehicle heaven or hell? Creating a transportation revolution that benefits all. https://greenlining.org/wpcontent/uploads/2019/01/R4_AutonomousVehiclesReportSingle_2019_2.pdf. Accessed 26 Sept 2019
Crute J, Riggs W, Chapin TS, Stevens L (2018) Planning for Autonomous Mobility. https://www.planning.org/publications/report/9157605/. Accessed 21 Sept 2018

Cugurullo F (2018) The origin of the smart city imaginary: from the dawn of modernity to the eclipse of reason. In: Lindner C and Meissner M (eds) The Routledge companion to urban imaginaries. Routledge, London UK, pp. 113-124

Cugurullo F, Acheampong RA, Gueriau M, Dusparic I (2021) The transition to autonomous cars, the redesign of cities and the future of urban sustainability Urban Geogr 42(6):833-859. https://doi.org/10.1080/02723638.2020.1746096

Daziano RA, Sarrias M, Leard B (2017) Are consumers willing to pay to let cars drive for them? Analyzing response to autonomous vehicles. Transpor Res Part C: Emerg Technol 78(May):150-164. https://doi.org/10.1016/ j.trc.2017.03.003

Dennis S, Paz A, Yigitcanlar T (2021) Perceptions and attitudes towards the deployment of autonomous and connected vehicles: insights from Las Vegas, Nevada. J Urban Technol 28(3-4):75-95. https://doi.org/10.1080/ 10630732.2021.1879606

Docherty I, Marsden G, Anable J (2018) The governance of smart mobility. Transp Res Part A: Policy Pract 115(Sept):114-125. https://doi.org/10.1016/ j.tra.2017.09.012

Dowling R, McGuirk P (2020) Autonomous vehicle experiments and the city. Urban Geography. https://doi.org/10.1080/02723638.2020.1866392

Duarte F, Ratti C (2018) The impact of autonomous vehicles on cities: a review. J Urban Technol 25(4):3-18. https://doi.org/10.1080/10630732.2018.1493883

Fagnant DJ, Kockelman K (2015) Preparing a nation for autonomous vehicles: opportunities, barriers and policy recommendations. Transp Res Part A: Policy Pract 77(Jul):167-181. https://doi.org/10.1016/j.tra.2015.04.003

Ferreira A, von Schönfeld KC, Tan W, Papa E (2020) Maladaptive planning and the pro-innovation bias: considering the case of automated vehicles. Urban Sci 4(3):41. https://doi.org/10.3390/urbansci4030041

Florida R (2014) The creative class and economic development. Econ Dev Quart 28(3):196-205. https://doi.org/10.1177/0891242414541693

Fraedrich E, Heinrichs D, Bahamonde-Birke FJ, Cyganski R (2019) Autonomous driving, the built environment and policy implications. Transp Res Part A: Pol and Pract 122(Apr):162-172. https://doi.org/10.1016/j.tra.2018.02.018

Freemark Y, Hudson A, Zhao J (2019) Are cities prepared for autonomous vehicles? J Am Plan Assoc 85(2):133-151. https://doi.org/10.1080/ 01944363.2019.1603760

Freemark Y, Hudson A, Zhao J (2020) Policies for autonomy: how american cities envision regulating automated vehicles. Urban Sci 4(4):55. https://doi.org/ 10.3390/urbansci4040055

Gao J, Ranjbari A, MacKenzie D (2019) Would being driven by others affect the value of travel time? Ridehailing as an analogy for automated vehicles. Transportation 46(6):2103-2116. https://doi.org/10.1007/s11116-019-10031-9

Gavanas N (2019) Autonomous road vehicles: challenges for urban planning in European cities. Urban Sci 3(2):61. https://doi.org/10.3390/urbansci3020061

Goodman EP, Powles J (2019) Urbanism under google: lessons from sidewalk Toronto. Fordham Law Rev 88(2):457-498. https://ir.lawnet.fordham.edu/flr/ vol $88 /$ iss $2 / 4$

Gruel W, Stanford JM (2016) Assessing the long-term effects of autonomous vehicles: a speculative approach. Transp Res Procedia 13:18-29. https:// doi.org/10.1016/j.trpro.2016.05.003

Grush B, Niles J (2019) Cities can prepare for autonomous vehicles now. Meeting of the Minds 02 Dec. https://meetingoftheminds.org/cities-can-prepare-forautonomous-vehicles-now- 32655 ? omhide $=$ true $\& \mathrm{mc}$ cid $=\mathrm{c} 240 \mathrm{bf} 5663 \mathrm{\& mc}$ eid=14b9efae76. Accessed 02 Dec 2019

Haboucha CJ, Ishaq R, Shiftan Y (2017) User preferences regarding autonomous vehicles. Transp Res Part C: Emerg Techno 78(May):37-49. https://doi.org/ 10.1016/j.trc.2017.01.010

Haque AM, Brakewood C (2020) A synthesis and comparison of american automated shuttle pilot projects. Case Stud Transp Policy 8(3):928-937. https:// doi.org/10.1016/j.cstp.2020.05.005

Harb M, Xiao Y, Circella G, Mokhtarian PL, Walker JL (2018) Projecting travelers into a world of self-driving vehicles: estimating travel behavior implications via a naturalistic experiment. Transportation 45(6):1671-1685. https:// doi.org/10.1007/s11116-018-9937-9

Harper CD, Hendrickson CT, Mangones S, Samaras C (2016) Estimating potential increases in travel with autonomous vehicles for the non-driving, elderly and people with travel-restrictive medical conditions. Transp Res Part C: Emerg Technol 72(Nov):1-9. https://doi.org/10.1016/j.trc.2016.09.003

Hawkins J, Nurul Habib K (2019) Integrated models of land use and transportation for the autonomous vehicle revolution. Transp Rev 39(1):66-83. https:// doi.org/10.1080/01441647.2018.1449033

Hecht G, (2001) Technology, politics, and national identity in France. In: Allen MT, Hecht G (eds) Technology of Power: essays in honor of Thomas Parke Hughes and Agatha Chipley Hughes. The MIT Press, Cambridge MA, pp. 253-294 
Henaghan J, Rouse D, Coyner K, Nisenson L, Jordan J (2018) Preparing communities for autonomous vehicles. Chicago IL. https://planning-orguploaded-media.s3.amazonaws.com/document/Autonomous-VehiclesSymposium-Report.pdf. Accessed 17 Feb 2019

Higgins CD, Kanaroglou PS (2016) Infrastructure or attraction? Image-led planning and the intangible objectives of rapid transit projects. J Plan Liter 31(4):452-462. https://doi.org/10.1177/0885412216667899

Hodgson D, Fred M, Bailey S, Hall P (eds) (2019) The projectification of the public sector. Routledge, New York NY

Huguenin A, Jeannerat H (2017) Creating change through pilot and demonstration projects: towards a valuation policy approach. Res Policy 46(3):624-635. https://doi.org/10.1016/j.respol.2017.01.008

Hulse LM, Xie H, Galea ER (2018) Perceptions of autonomous vehicles: relationships with road users, risk, gender and age. Safety Sci 102(Feb):1-13. https:// doi.org/10.1016/j.ssci.2017.10.001

Jin X, Rahimi A, Azimi G (2020) The impacts of emerging mobility options and vehicle technologies on travel behavior. https://scholarcommons.usf.edu/cgi/ viewcontent.cgi article $=1252 \&$ context $=$ cutr_nctr. Accessed 28 Jan 2021

Johnson M, Riggs W (2019) Shaping urban environments around transportation innovation. In: Riggs W (ed) Disruptive transport: driverless cars, transport innovation and the sustainable city of tomorrow. Routledge, New York NY, pp. $39-50$

Karlin-Resnick J, Tumlin J, Merritt M (2019) Policy and program innovation in anticipation of the new mobility future. In: Riggs W (ed) Disruptive transport: driverless cars, transport innovation and the sustainable city of tomorrow. Routledge, New York NY, pp. 98-124

Karvonen A, Evans J, van Heur B (2014) The politics of urban experiments: radical change or business as usual? In: Hodson M, Marvin S (eds) After Sustainable cities? Routledge, New York NY

Kassens-Noor E, Wilson M, Cai M, Durst N, Decaminada T (2021) Autonomous vs. self-driving vehicles: the power of language to shape public perceptions. J Urban Technol 28(3-4):5-24. https://doi.org/10.1080/10630732.2020.1847983

Khoury A (2018) You can now hail a ride in a fully autonomous vehicle, courtesy of Waymo. Digital Trends 17 Feb. https://www.digitaltrends.com/cars/ waymo-now-a-full-ride-hailing-service/. Accessed 28 Aug 2018

Kisner C, Fillin-Yeh K, Bharadwaj S, Schmidt C, Abdulsamad M, Engel A (2019) Blueprint for Autonomous Urbanism, Second Edition. https:// www.dropbox.com/s/5n6xhvkntya8ifa/NACTO_Blueprint_2nd_Edition_ singlepages_small.pdf?dl=1. Accessed 12 Sept 2019

Kitchin R (2014) The real-time city? big data and smart urbanism. GeoJournal 79(1):1-14. https://doi.org/10.1007/s10708-013-9516-8

Kitchin R (2015) Making sense of smart cities: addressing present shortcomings. Cambridge J Region Econ Soc 8(1):131-136. https://doi.org/10.1093/cjres/ rsu027

Kitchin R (2021) Decentering the Smart City. https://progcity.maynoothuniversity.ie/ wp-content/uploads/2021/01/PC-45-Decentring-the-smart-city.pdf. Accessed 06 Sept 2021

Knorr A (2018) Designing for future mobility: developing a framework for the livable future city. https://perkinswill.com/wp-content/uploads/2019/09/ Designing_for_Future_Mobility_Report.pdf. Accessed 11 Apr 2019

Krivý M (2018) Towards a critique of cybernetic urbanism: the smart city and the society of control. Plan Theor 17(1):8-30. https://doi.org/10.1177/ 1473095216645631

Lari A, Douma F, Onyiah I (2015) Self-driving vehicles and policy implications: current status of autonomous vehicle development and minnesota policy implications. Minn J Law Sci Technol 16(2):735-769. https://scholarship.law.umn.edu/mjlst/ vol16/iss $2 / 5$

Legacy C, Ashmore D, Scheurer J, Stone J, Curtis C (2019) Planning the Driverless City. Transp Rev 39(1):84-102. https://doi.org/10.1080/ 01441647.2018 .1466835

Litman T (2020) Autonomous vehicle implementation predictions: implications for transport planning. https://www.vtpi.org/avip.pdf. Accessed 07 Jan 2021

Mahmoodi Nesheli M, Li L, Palm M, Shalaby A (2021) Driverless shuttle pilots: lessons for automated transit technology deployment. Case Stud Transp Policy 9(2):723-742. https://doi.org/10.1016/j.cstp.2021.03.010

McAslan D, Gabriele M, Miller TR (2021) Planning and POlicy Directions for Autonomous Vehicles in Metropolitan Planning Organizations (MPOs) in the United States. J Urban Technol. 28(3-4):175-201. https://doi.org/ $10.1080 / 10630732.2021 .1944751$

Millard-Ball A (2019) The autonomous vehicle parking problem. Transp Policy 75(Mar):99-108. https://doi.org/10.1016/j.tranpol.2019.01.003

Miller T, McAslan D (2019) Self-driving ride-share service 'Waymo One' has launched: what's next for cities? Meeting of the Minds 23 Jan. https:// meetingoftheminds.org/self-driving-ride-share-service-waymo-one-haslaunched-whats-next-for-cities-29661. Accessed 27 Oct 2019

Miller TR (2020) Imaginaries of sustainability: the techno-politics of smart cities. Sci Culture 29(3):365-387. https://doi.org/10.1080/09505431.2019.1705273
National League of Cities. 2017. Autonomous vehicles: a policy preparation guide. https://www.bafuture.org/sites/default/files/key-topics/attachments/NLC AV Policy Prep Guide 4.11.17.pdf. Accessed 28 Aug 2018

Nikitas A, Vitel AE, Cotet C (2021) Autonomous vehicles and employment: an urban futures revolution or catastrophe? Cities 114. https://doi.org/10.1016/ j.cities.2021.103203

Pankratz DM, Nuttall K, Eggers WD, Turley M (2018) Regulating the future of mobility: balancing innovation and the public good in autonomous vehicles, shared mobility, and beyond. https://www2.deloitte.com/us/en/insights/ focus/future-of-mobility/regulating-transportation-new-mobilityecosystem.html. Accessed 08 Jul 2020

Pfotenhauer SM, Juhl J, Aarden E (2019) Challenging the 'deficit model' of innovation: framing policy issues under the innovation imperative. Res Policy 48(4):895-904. https://doi.org/10.1016/j.respol.2018.10.015

Sadowski J (2020) Too smart: how digital capitalism is extracting data, controlling our lives, and taking over the world. The MIT Press, Cambridge MA

Sadowski J, Pasquale F (2015) The spectrum of control: a social theory of the smart city. First Monday 20 (7). https://ssrn.com/abstract $=2653860$

Savini F, Bertolini L (2019) Urban experimentation as a politics of niches. Environ Plan A: Econ Space 51(4):831-848. https://doi.org/10.1177/0308518X19826085

Schoettle B, Sivak M (2014) A survey of public opinion about autonomous and selfdriving vehicles in the U.S., the U.K., and Australia. https://hdl.handle.net/ 2027.42/108384. Accessed 13 Jan 2021

von Schönfeld KC, Ferreira A (2021) Urban planning and european innovation policy: achieving sustainability, social inclusion, and economic growth? Sustainability 13(3):1137. https://doi.org/10.3390/su13031137

SDOT (2017) New mobility playbook. Seattle WA. https://www.seattle.gov/ Documents/Departments/SDOT/NewMobilityProgram/ NewMobility_Playbook_9.2017.pdf. Accessed 18 Oct 2018

Shaw K, Montana G (2016) Place-making in megaprojects in Melbourne. Urban Policy Res 34(2):166-189. https://doi.org/10.1080/08111146.2014.967392

Shove E, Walker G (2007) Caution! transitions ahead: politics, practice, and sustainable transition management. Environ Plann A Econ Space 39(4):763-770. https://doi.org/10.1068/a39310

Soteropoulos A, Berger M, Ciari F (2019) Impacts of automated vehicles on travel behaviour and land use: an international review of modelling studies. Transp Rev 39(1):29-49. https://doi.org/10.1080/01441647.2018.1523253

Steckler B, Coia J, Howell A, Kaplowitz G, Stoll M, Yang H (2020) Perfecting policy with pilots: new mobility and AV urban delivery pilot project assessment https://cpb-us-el.wpmucdn.com/blogs.uoregon.edu/dist/f/13615/files/2020/05/ 2020-Perfecting-Policy-with-Pilots-UNext-Online.pdf. Accessed 27 May 2020

Steckler B, Howell A, Larco N, Kaplowitz G (2021) A framework for shaping the deployment of autonomous vehicles and advancing equity outcomes. https:// www.urbanismnext.org/resources/a-framework-for-shaping-the-deploymentof-autonomous-vehicles-and-advancing-equity-outcomes. Accessed 24 Jan 2021

Stilgoe J (2018a) We need new rules for self-driving cars. Issue Sci Technol 34(3):52-57. https://issues.org/we-need-new-rules-for-self-driving-cars/

Stilgoe J (2018b) Machine learning, social learning and the governance of selfdriving cars. Soc Stud Sci 48(1):25-56. https://doi.org/10.1177/ 0306312717741687

Stilgoe J, Cohen T (2021) Rejecting acceptance: learning from public dialogue on self-driving vehicles. science and public policy. https://doi.org/10.1093/scipol/ scab060

Talen E (2015) Do-it-yourself urbanism. J Plan Hist 14(2):135-148. https://doi.org/ $10.1177 / 1538513214549325$

Tettamanti T, Varga I, Szalay Z (2016) Impacts of autonomous cars from a traffic engineering perspective. periodica polytechnica transportation engineering. https://doi.org/10.3311/PPtr.9464

Torrens J, von Wirth T (2021) Experimentation or projectification of urban change? A critical appraisal and three steps forward. Urban Transform 3(1):8 https://doi.org/10.1186/s42854-021-00025-1

Vanolo A (2014) Smartmentality: the smart city as disciplinary strategy. Urban Stud 51(5):883-898. https://doi.org/10.1177/0042098013494427

Verrest H, Pfeffer K (2019) Elaborating the urbanism in smart urbanism: distilling relevant dimensions for a comprehensive analysis of smart city approaches. Inform Commun Soc 22(9):1328-1342. https://doi.org/10.1080/ 1369118X.2018.1424921

Webb D (2018) Tactical urbanism: delineating a critical praxis. Plan Theor Pract 19(1):58-73. https://doi.org/10.1080/14649357.2017.1406130

Wiig A (2015) IBM's smart city as techno-utopian policy mobility. City 19(2-3):258-273. https://doi.org/10.1080/13604813.2015.1016275

van Winden W, van den Buuse D (2017) Smart city pilot projects: exploring the dimensions and conditions of scaling up. J Urban Technol 24(4):51-72. https://doi.org/10.1080/10630732.2017.1348884

von Wirth T, Fuenfschilling L, Frantzeskaki N, Coenen L (2019) Impacts of urban living labs on sustainability transitions: mechanisms and strategies for 
systemic change through experimentation. Eur Plan Stud 27(2):229-257. https://doi.org/10.1080/09654313.2018.1504895

Yigitcanlar T, Wilson M, Kamruzzaman M (2019) Disruptive impacts of automated driving systems on the built environment and land use: an urban planner's perspective. J Open Innov Technol Market Complex 5(2):24. https://doi.org/10.3390/joitmc5020024

Zhang W, Guhathakurta S (2021) Residential location choice in the era of shared autonomous vehicles. J Plan Educ Res 41(2):135-148. https://doi.org/10.1177/ 0739456X18776062

Zhang W, Guhathakurta S, Khalil EB (2018) The impact of private autonomous vehicles on vehicle ownership and unoccupied VMT generation. Transp Res Part C: Emer Technol 90(May):156-165. https://doi.org/10.1016/ j.trc.2018.03.005

Zmud J, Goodin G, Moran M, Kalra N, Thorn E (2017) Advancing automated and connected vehicles: policy and planning strategies for state and local transportation agencies. Transportation Research Board, Washington DC. https:// doi.org/10.17226/24872

\section{Acknowledgements}

This work was supported by a grant from the TOMNET University Transportation Center at Arizona State University, funded by the U.S. Department of Transportation. The authors would also like to thank to all those who took the time to participate in interviews with our research team during this project.

\section{Funding}

Open access funding provided by Chalmers University of Technology.

\section{Competing Interests}

The authors declare no competing interests.

\section{Ethical approval}

This project was approved by the Arizona State University Institutional Review Board and all research was performed in accordance with the relevant guidelines and regulations.

\section{Informed consent}

Informed consent was obtained from all interview participants in this study.

\section{Additional information}

Correspondence and requests for materials should be addressed to Devon McAslan.

Reprints and permission information is available at http://www.nature.com/reprints

Publisher's note Springer Nature remains neutral with regard to jurisdictional claims in published maps and institutional affiliations.

(c) (i) Open Access This article is licensed under a Creative Commons Attribution 4.0 International License, which permits use, sharing, adaptation, distribution and reproduction in any medium or format, as long as you give appropriate credit to the original author(s) and the source, provide a link to the Creative Commons license, and indicate if changes were made. The images or other third party material in this article are included in the article's Creative Commons license, unless indicated otherwise in a credit line to the material. If material is not included in the article's Creative Commons license and your intended use is not permitted by statutory regulation or exceeds the permitted use, you will need to obtain permission directly from the copyright holder. To view a copy of this license, visit http://creativecommons.org/ licenses/by/4.0/.

() The Author(s) 2021 